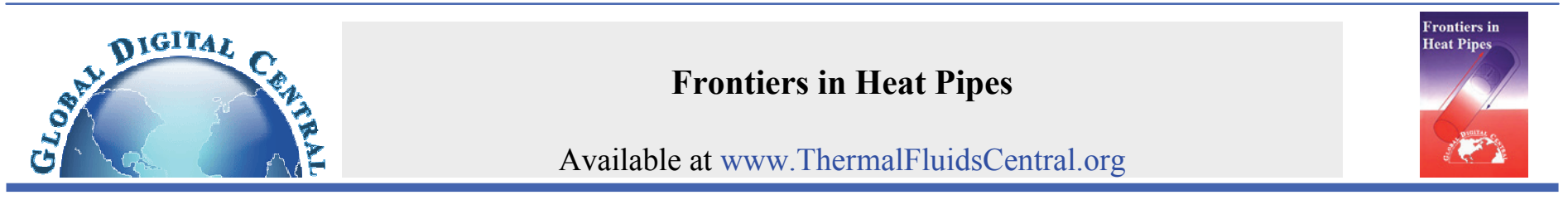

\title{
AN EXPERIMENTAL INVESTIGATION OF HYBRID OSCILLATING HEAT PIPE
}

\author{
C. D. Smoot, H. B. $\mathrm{Ma}^{*}$ \\ Department of Mechanical \& Aerospace Engineering, University of Missouri, Columbia, Missouri, 65211, USA
}

\begin{abstract}
A novel oscillating heat pipe (OHP) has been constructed and experimentally investigated featuring a meandering channel formed entirely by a wicking structure. The hybrid approach utilizes the wicking structure found in traditional heat pipes, while also utilizing the meandering channels and plug flow of OHPs. Water and acetone were both tested with acetone demonstrating higher peak performance and water demonstrating a wider operating range. While OHPs typically require a high startup power, the hybrid approach presented achieves startup at very low power input and demonstrates a significant improvement in performance over the same device without any working fluid.

Keywords: Phase Change, Capillary Wick, Pulsating Heat Pipe
\end{abstract}

\section{INTRODUCTION}

As electronic devices continue to push the boundaries of both power and ever shrinking size, thermal management issues are becoming important design limitations for future technology. Due to high heat transport capability, passive heat pipes (Chang et al., 2008; Lee et al., 2007; Xie et al., 1998) have been used widely to address the cooling needs in many applications, such as laptops and high-powered desktop computers. Because the conventional heat pipe utilizes capillary force to pump the working fluid from the condenser to the evaporator, the capillary flow has the limitation that prevents handling high heat flux applications such as radar or laser die cooling. In addition to the capillary limitation, other limitations including the boiling and sonic limits prevent fluid from returning to the evaporator (Faghri, 1995).

By contrast, oscillating heat pipes have not demonstrated these limitations. Research has suggested that OHPs have the capability to transfer large quantities of heat with small temperature differences. Wilson et al. (accepted) conducted experiments using tube-style OHPs with neutron radiography to provide visual evidence of the fluid behavior. Ma et al. (2006) and Ma et al. (2006) provided evidence that the performance may be significantly enhanced using nanoparticles in the working fluid. Borgemeyer and $\mathrm{Ma}$ (2007), Thompson et al. (2009), and Thompson and Ma (2010) have shown that flat plate OHPs, in which the meandering channel is carved from a solid piece of material rather than formed by a wrapped tube, provide much more compact solutions to heat transfer applications while still utilizing the OHPs superior performance to conventional heat pipes. KammuangLue et al. (2009) conducted experiments studying various design factors of OHPs to determine a correlation to predict the maximum heat flux. Soponpongpipat et al. (2009) extensively researched the startup behavior of OHPs, concluding that OHPs require a specific minimum power level associated with a suitable temperature difference between the evaporator and condenser section to achieve startup. In other words, the OHP does not function well at low power input.
Zuo et al. (1999) created an OHP with a wick structure and found the wick aided liquid distribution and allowed for higher heat fluxes to be transported. Holley and Faghri (2005) developed a model to predict the performance of an OHP with a wick structure and varying channel diameter. Xu et al. (2009), modeled OHP performance studying only the effect of including a wick structure with an OHP. The study concludes that a wick structure within an OHP will increase latent heat transfer as well as sensible heat transfer and that the increase in latent heat transfer results in increased vapor plug temperature and pressure as well as increased liquid plug oscillating amplitude. However, these investigations have not addressed the low power effect on the heat transport capability in an OHP.

In order to address the low power input effect on the heat transfer performance of an OHP, a hybrid OHP is developed. A series of meandering channels, as that in an OHP, are formed entirely by a wicking material, as that in a conventional heat pipe (CHP) or vapor chamber (VC). The effects of liquid charging ratio, operating temperature, working fluid type, and gravity are conducted in order to find the primary factors affecting the heat transfer performance in the hybrid OHP investigated herein.

\section{INTEGRATED HYBRID OHP}

The concept for the integrated hybrid OHP is shown in Fig. 1. The integrated hybrid name is used to illustrate the fact that the device combines concepts from both CHP/VCs and OHPs together in such a way that they are completely dependent on one another and not separate entities. The OHP channel is formed by a wick structure rather than a typical OHP's solid metal wall. If the heat pipe is charged with a very low filling ratio, it will perform very similar to a traditional heat pipe with vapor occupying the channel and liquid only being transported within the wick. However when filled with larger filling ratios, as used in OHPs, the wick will be saturated, leaving only the open channel for the remaining fluid. Because of the small diameter channel, the remaining fluid will form liquid plugs as seen in OHPs. When heat is applied, evaporation from the wick will take place, building vapor

Corresponding author.Email: Mah@missouri.edu 
pressure between liquid plugs located near the evaporator, causing motion similar to that seen with a typical OHP. In addition to the oscillating motion of the liquid plugs and vapor bubbles, some of liquid flows through wick structure as shown in Fig. 2.

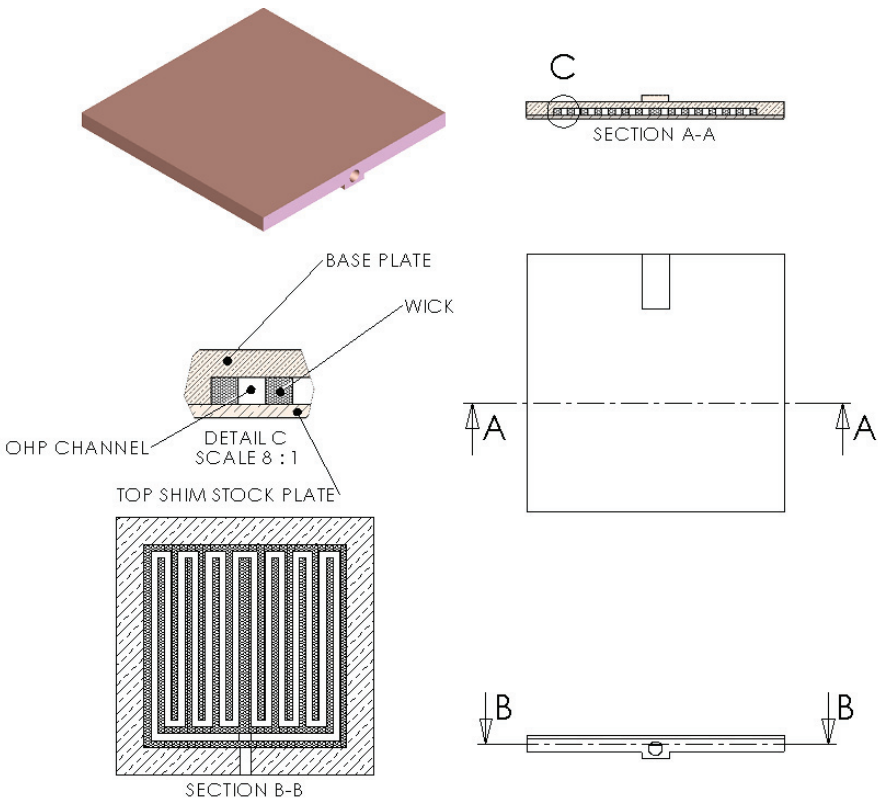

Fig. 1 Schematic of Integrated Hybrid OHP

The hybrid OHP design as shown in Fig. 1 is similar to a flat plate OHP in that the channels were created inside a material rather than by tubing. As with an OHP, the channel must meander back and forth over the evaporator and condenser sections of the device and as with an OHP the design may be open or closed loop. The current design features a $0.794 \times 0.794 \mathrm{~mm} 2$ meandering channel formed on the sides by a wick structure, and capped on top and bottom by solid copper sheet. The wick structure was made from $50 \mu \mathrm{m}$ diameter sintered copper powder. The design features 7 turns in a closed loop configuration, and the total length and width of the heat pipe is $30 \mathrm{~mm} \times 30 \mathrm{~mm}$.

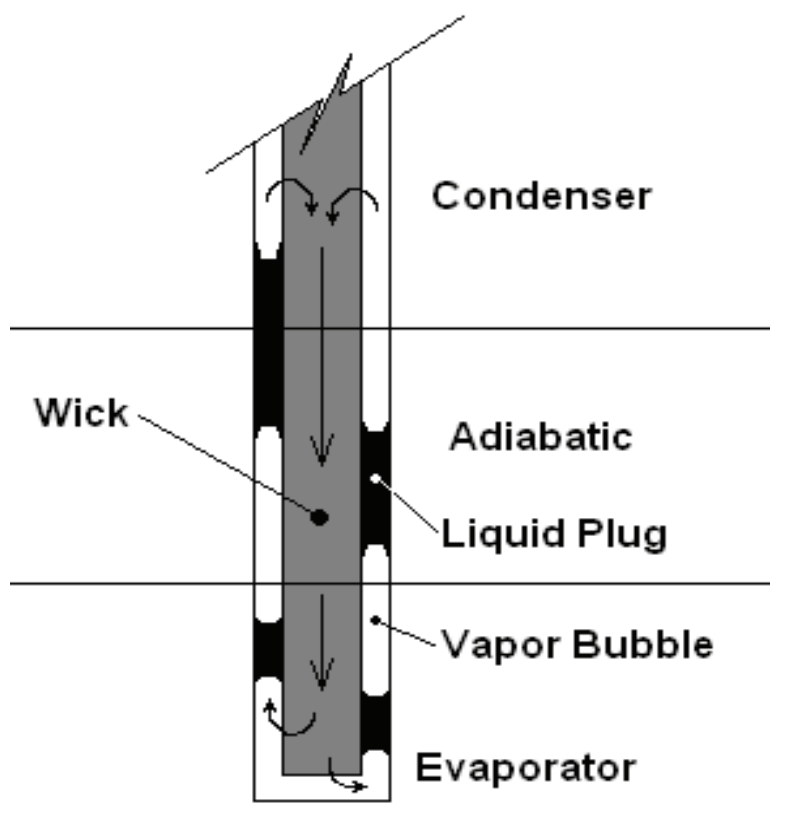

Fig. 2 Schematic of hybrid OHP fluid flow

\section{EXPERIMENTAL SETUP}

Figure 3 illustrates the layout of the overall experimental system. The system consists of a stand with angle adjustment, a heat pipe assembly, a constant temperature cooling bath, a data acquisition system (DAQ), a personal computer, a power supply, a digital multi-meter (DMM), and type $\mathrm{T}$ thermocouples. A test stand was constructed from $80 / 20$ brand extruded aluminum pieces. It is capable of 180 degrees of vertical angle adjustment and allows for a quick change in orientation for tests of gravitational dependence. It was designed to accept a wide range of heat pipe experiments. For this design, the test stand mounts were used to hold a heat pipe assembly. The heat pipe assembly consists of the heat pipe to be tested, a cooling block, three chip heaters and heater block, thermocouples, and aluminum blocks (not shown) to hold the assembly together. The assembly was wrapped by fiberglass insulation and aluminum foil. The heater block is $0.79 \mathrm{~mm}$ thick, with a $10 \times 30$ $\mathrm{mm} 2$ area contact surface. Three chip heaters, capable of $250 \mathrm{~W}$ each, were soldered to the block. The heat pipe was placed such that there is a $20 \times 30 \mathrm{~mm} 2$ cooling area. Temperature data was taken using 9 type $\mathrm{T}$ thermocouples. Temperature difference calculations were made between the average of thermocouples 1-3 and the average of thermocouples 7-9. The data was recorded using a National Instruments SCXI-1000 DAQ and personal computer running National Instruments LabVIEW SignalExpress 3.0. Power input was controlled using a $130 \mathrm{~V}$ AC variac while the DAQ computed the power input from voltage and current measurements. A Julabo F33 constant temperature cooling bath circulated water through the cooling block at a designed temperature.

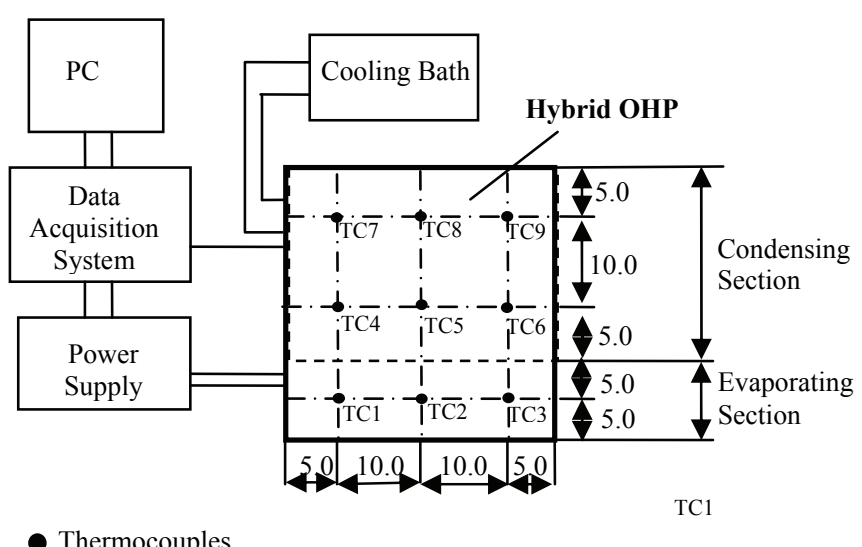

Fig. 3 Schematic of experimental setup (unit:mm)

For the tests, data was recorded for both transient and steady state operation at each power level. Power was increased in $10 \mathrm{~W}$ increments until the evaporator temperature reached $100{ }^{\circ} \mathrm{C}$ (chosen to protect the chip heaters from overheating). Testing includes orientation, filling ratio $(28 \%, 46 \%$ and $80 \%$ for acetone and $32 \%$, $53 \%$, and $82 \%$ for water), condenser temperature $\left(20{ }^{\circ} \mathrm{C}\right.$ and $\left.60{ }^{\circ} \mathrm{C}\right)$, and fluid (acetone and water) effects on the heat pipe operation. The orientation effect was conducted horizontally with heating on one side (horizontal), vertically with heating on the top section (top heating), and vertically with heating on the bottom section (bottom heating), respectively.

\section{RESULTS AND DISCUSSION}

In order to demonstrate the heat transfer performance of the hybrid OHP developed herein, the empty hybrid OHP without working fluid was tested as well. The temperature difference ratio of the empty OHP to the charged one is used to evaluate the heat transfer performance of the hybrid OHP. Figure 4 illustrates the acetone hybrid OHP's behavior at a low filling ratio of $28 \%$, a power input of $20 \mathrm{~W}$, and in the bottom heating orientation. Three representative thermocouples of 
$\mathrm{TC} 2$, TC5, and TC8 were chosen to measure temperature variations occurring in the evaporating and condensing sections. Oscillation was observed in the evaporator at $60{ }^{\circ} \mathrm{C}$, but was not obvious from the condenser thermocouples. As an OHP typically demonstrates oscillations for every section of a heat pipe, this behavior is somewhat unexpected. However it is not uncommon for an OHP to demonstrate higher oscillating amplitude in the adiabatic or evaporator section than that in the condenser section. Nevertheless, the oscillating motion is not particularly strong with the low filling ratio at high cooling bath temperatures, despite showing strong heat transfer performance as illustrated in Fig. 5. The oscillations appear to be more vigorous at the lower cooling bath temperature, and can be seen in the condenser section as well as the evaporator. This is likely a result of a slightly higher surface tension at the colder temperatures allowing the liquid slugs to hold to the sintered particle wall stronger.

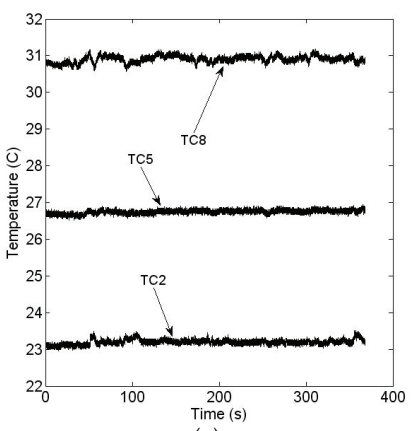

(a)

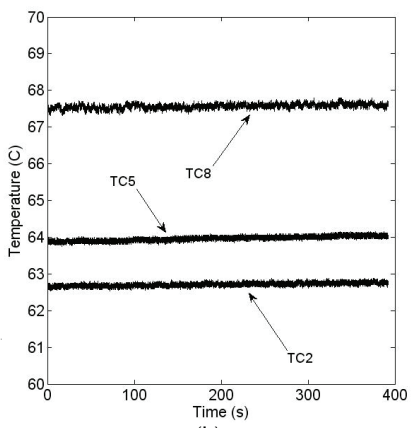

(b)
Fig. 4 Temperature variations at (a) $20{ }^{\circ} \mathrm{C}$ and (b) $60{ }^{\circ} \mathrm{C}$ (filling ratio $=28 \%$, power input $=20 \mathrm{~W}$, working fluid: acetone, and heating mode: vertical bottom heating)

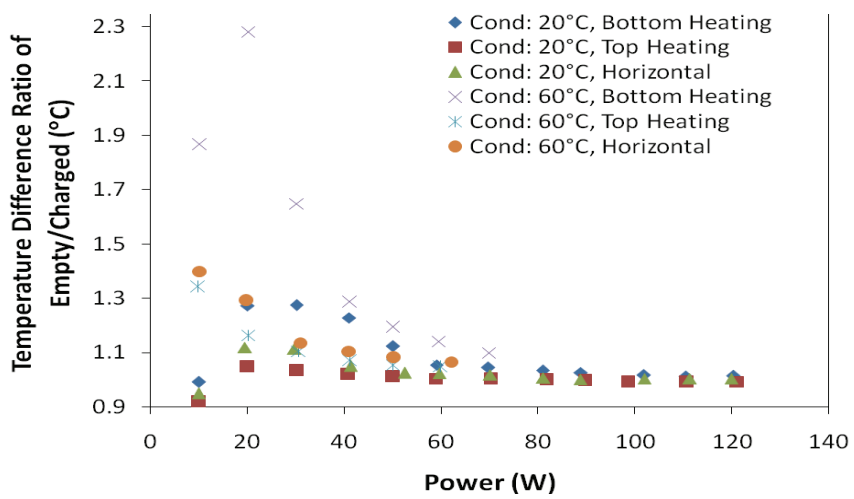

Fig. 5 Power input effect on the temperature difference at $28 \%$ filling ratio with acetone.

The heat pipe at $60{ }^{\circ} \mathrm{C}$ in the bottom heating orientation begins oscillating at the first power input of $10 \mathrm{~W}$; however once beyond $30 \mathrm{~W}$ the oscillations become harder to distinguish from thermocouple noise. It is possible the liquid is accumulating in the condenser section and the heat pipe became a typical CHP or VC. Another possibility is that the liquid slugs are moving faster within the channel, and the thermal mass of the heat pipe shell is unable to transmit the temperature spikes quickly enough to be read by the thermocouples. These may be confirmed using a visual technique such as neutron imaging. An interesting behavior exhibited by the heat pipe at $60 \mathrm{C}$ cooling bath temperature is the performance in less-than-ideal operating orientations. The heat pipe demonstrated more than a $30 \%$ increase in performance over the empty heat pipe in the vertical top heating and horizontal orientation at a low power input. At $20{ }^{\circ} \mathrm{C}$ in the bottom heating orientation, the heat pipe does not start up at $10 \mathrm{~W}$, but rather at $20 \mathrm{~W}$ of input power. This later startup is also plagued with worse overall performance compared to the results at $60{ }^{\circ} \mathrm{C}$. Regardless of cooling bath temperature or orientation, the heat pipe appears to have an ideal operating range. Unlike typical OHPs, the temperature difference curves have distinct peaks. Each curve appears to peak at low power for this filling ratio and, past this point, decay to the empty device's performance.

The hybrid OHP produces similar results when the filling ratio is increased to $46 \%$. Figure 6 illustrates the hybrid OHP's behavior with acetone at $30 \mathrm{~W}$ of input power in the bottom heating orientation. Three representative thermocouples are chosen to depict the heat pipe's behavior; TC3, TC6, and TC9. As seen at the lower filling ratio, oscillating motion is difficult to see at the high cooling bath temperature, if it exists at all. While it is likely there exists oscillating motion given the substantial improvement over the empty device, this cannot be confirmed without visual techniques. While temperature oscillations are visible at the lower cooling bath temperature, the increase in filling ratio has clearly resulted in significantly more vigorous oscillations. The oscillations carry through the heat pipe, from the evaporator through the condenser region.

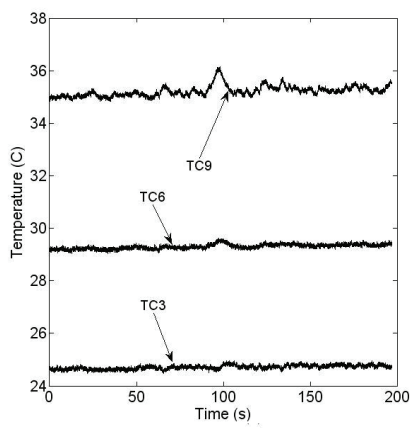

(a)

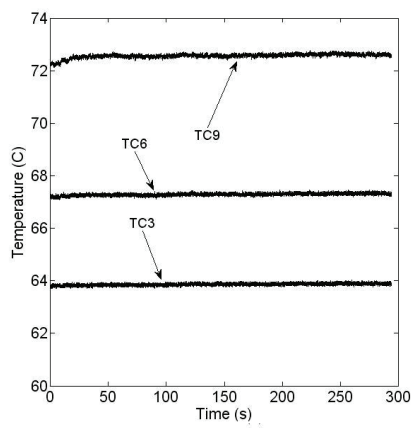

(b)
Fig. 6 Temperature variations at (a) $20{ }^{\circ} \mathrm{C}$ and (b) $60{ }^{\circ} \mathrm{C}$ (filling ratio $=46 \%$, power input $=30 \mathrm{~W}$, working fluid: acetone, and heating mode: vertical bottom heating)

Figure 7 illustrates the heat transfer performance with the higher filling ratio. With a $60{ }^{\circ} \mathrm{C}$ cooling bath temperature, the heat pipe starts up at the first power interval. The $60{ }^{\circ} \mathrm{C}$ cooling bath temperature results in the best performance in each orientation. Overall performance is higher than that with the lower filling ratio for most orientations and cooling bath set-points, however one notable exception is the top heating orientation at $60{ }^{\circ} \mathrm{C}$; the heat pipe fails to exceed the $30 \%$ improvement seen with the low filling ratio. The device again demonstrates the best performance at lower power levels, showing an ideal, peak range of input power, and decaying to the empty device operation as power increases. However because the overall performance is better, the fall-off occurs at a slightly higher input power than that of the low filling ratio.

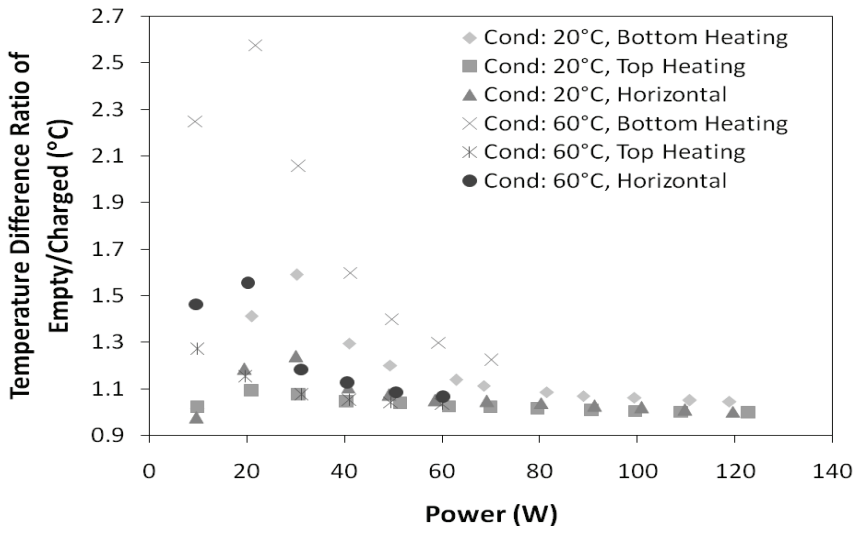

Fig. 7 Power input effect on the temperature difference at $46 \%$ filling ratio with acetone. 
When the filling ratio is increased to $80 \%$, oscillations are virtually impossible to observe from the temperature data. However at this high filling ratio, the startup behavior, as typically seen with OHPs, is clearly visible during the transient tests. Figure 8 shows the startup behavior at the $20{ }^{\circ} \mathrm{C}$ and $60{ }^{\circ} \mathrm{C}$ cooling bath set-points. The startup at $20{ }^{\circ} \mathrm{C}$ occurs when power is increased from $50 \mathrm{~W}$ to $60 \mathrm{~W}$ while startup occurs at 60 ${ }^{\circ} \mathrm{C}$ when power is increased from $40 \mathrm{~W}$ to $50 \mathrm{~W}$. This echoes the behavior at lower filling ratios when it is observed that the oscillations began at the first power input for $60{ }^{\circ} \mathrm{C}$ and at $20 \mathrm{~W}$ for $20{ }^{\circ} \mathrm{C}$. Figure 9 illustrates the overall behavior of the device at the high filling ratio, and as can clearly be seen, the heat pipe performance appears to improve with increased power. This is similar to the behavior observed at lower filling ratios, in that there appears to be an ideal range of input power, however unlike the lower filling ratios where the device worked best at low power, the higher filling ratio hybrid demonstrates better performance at higher power input. At best, the hybrid demonstrates less than $20 \%$ improvement over the empty device at the high filling ratio. In fact, the heat pipe's performance is only noteworthy in the bottom heating orientation, as the rest demonstrate a negligible improvement over the empty device.

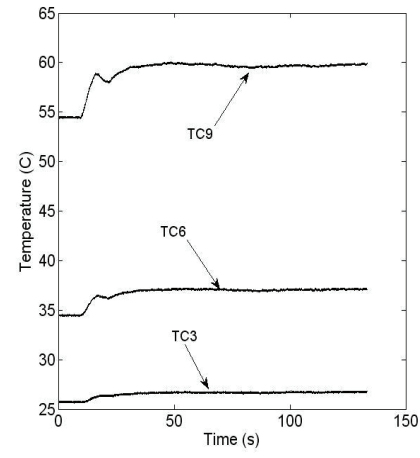

(a)

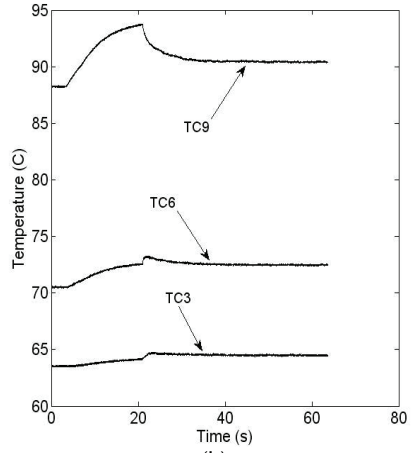

(b)
Fig. 8 Temperature variations at a) $20{ }^{\circ} \mathrm{C}$ with power input from 50 $\mathrm{W}$ to $60 \mathrm{~W}$ and b) $60^{\circ} \mathrm{C}$ with power input from $40 \mathrm{~W}$ to $50 \mathrm{~W}$ (filling ratio $=80 \%$, working fluid: acetone, and heating mode: vertical bottom heating)

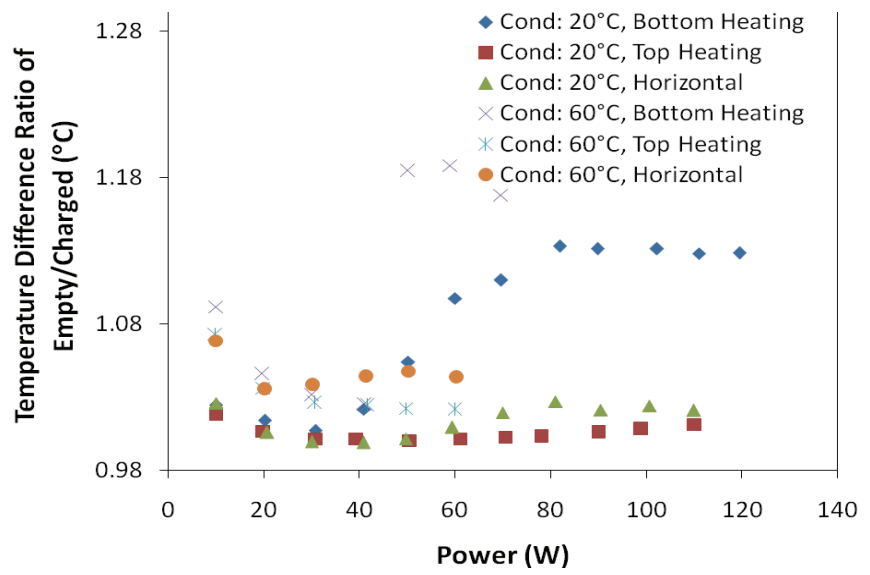

Fig. 9 Power input effect on the temperature difference at $80 \%$ filling ratio with acetone.

Water displays trends which are similar in some ways, but quite different in others. Figure 10 shows the hybrid's performance with a $32 \%$ filling ratio at $30 \mathrm{~W}$ in the bottom heating orientation at both $20{ }^{\circ} \mathrm{C}$ and $60{ }^{\circ} \mathrm{C}$ for selected thermocouples (TC3, TC6, and TC9). Unlike the acetone charged heat pipe, the water charged device demonstrates better oscillations at the higher temperature. Another significant difference from the acetone charged heat pipe is the oscillation of the temperatures. The device displays very abrupt temperature changes followed by little or no change for seconds at a time before another abrupt temperature change occurs, repeating this cycle throughout the test. It is possible this phenomenon is the result of inactivity until a suitable instability is created resulting in a burst of fluid movement until equilibrium is again obtained. This behavior is occasionally seen with larger, tube-style OHPs at low power, right at the startup point.

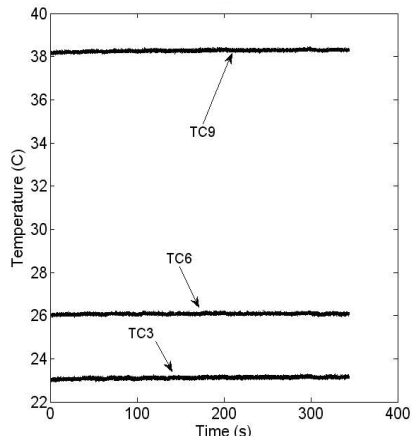

(a)

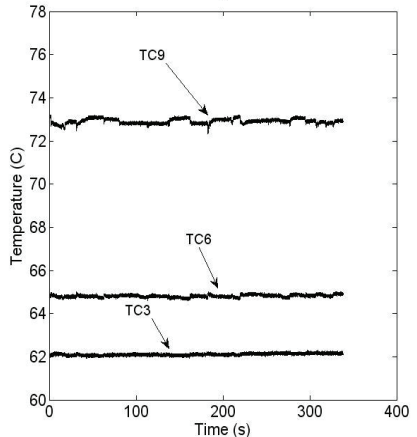

(b)
Fig. 10 Temperature variations at a) $20^{\circ} \mathrm{C}$ and b) $60{ }^{\circ} \mathrm{C}$ (filling ratio $=32 \%$, power input $=30 \mathrm{~W}$, working fluid: water, and heating mode: vertical bottom heating)

Figure 11 illustrates the hybrid OHP's overall performance with the $32 \%$ filling ratio and water as the working fluid. Peak performance is substantially lower than that of acetone; however the working range of the heat pipe is considerably larger with water. The water charged heat pipe remains at or above $30 \%$ improvement over the empty device from $20 \mathrm{~W}$ to $90 \mathrm{~W}$ of input power when the cooling bath temperature is 60 ${ }^{\circ} \mathrm{C}$ whereas the acetone charged device could only sustain performance over $30 \%$ improvement from $10 \mathrm{~W}$ to $40 \mathrm{~W}$ with a similar filling ratio and the same cooling bath temperature. This behavior is not just limited to the bottom heating orientation; in fact, at $60{ }^{\circ} \mathrm{C}$, the water charged heat pipe operated over a wider range than the acetone charged heat pipe in all three orientations. In the top heating orientation, the water charged hybrid consistently operates with a $20 \%$ or greater improvement over the empty device. Another difference from acetone to water is that the water charged hybrid does not consistently decay to the empty device's performance as the acetone charged hybrid did. In all orientations and both cooling bath set points, the water charged heat pipe displayed a minimum $10 \%$ improvement over the empty device at the highest power input. While a $10 \%$ improvement is not stunning, it offers yet more evidence that when charged with water, the hybrid OHP operates over a wider range than when charged with acetone.

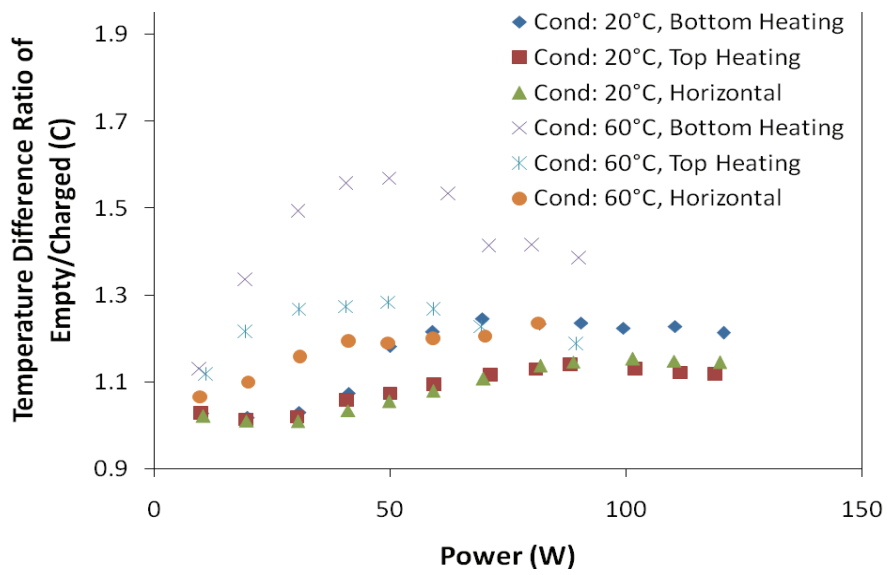

Fig. 11 Power input effect on the temperature difference at $32 \%$ filling ratio with water. 
The higher filling ratios of water did not demonstrate temperature oscillations, in much the same way as seen with the highest filling ratio of acetone. Figures 12 and 13 display the overall performance of the heat pipe with $53 \%$ and $82 \%$ filling ratios, respectively. As clearly seen in Fig. 12, the overall performance of the device is lower than that of the $32 \%$ filling ratio. The hybrid still offers a wide range of operation however the overall performance is too low to be considered worthwhile unless operating above $70 \mathrm{~W}$ in the inverted orientation at the high cooling bath temperature. Figure 13 clearly illustrates that the very high filling ratio with water offers subpar performance. Only two of the power inputs managed to offer $10 \%$ or more improvement over the empty device whereas the acetone charged device, which also did not perform well at the highest filling ratio.

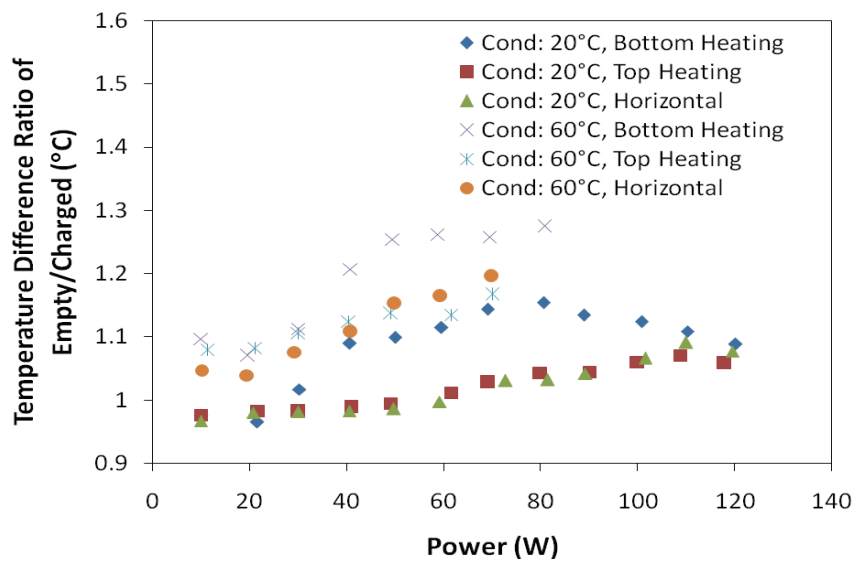

Fig. 12 Power input effect on the temperature difference at 53\% filling ratio with water.

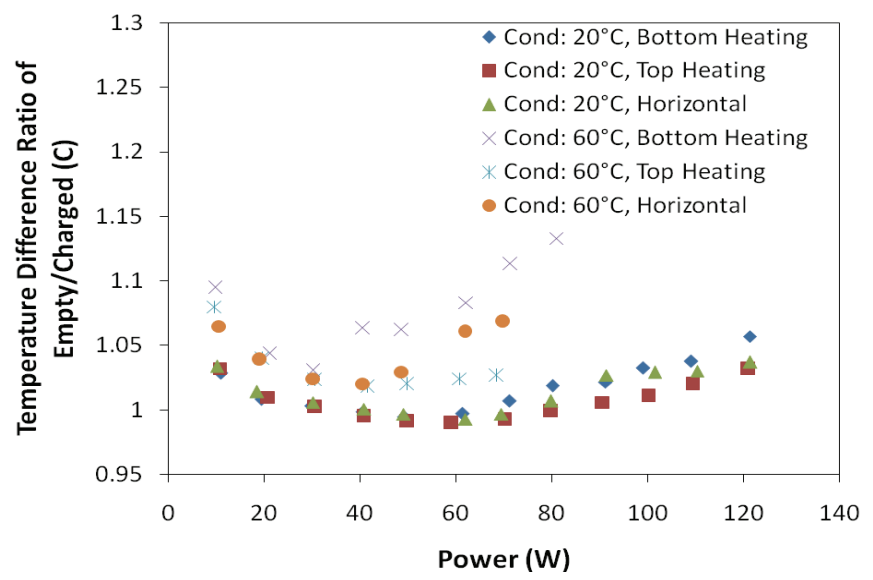

Fig. 13 Power input effect on the temperature difference at $82 \%$ filling ratio with water.

\section{CONCLUSIONS}

A novel hybrid OHP has been constructed and tested, combining the principles of vapor chambers and oscillating heat pipes to eliminate, or significantly reduce, the startup power requirement found in typical OHPs. The device utilizes a wick structure to form the walls of the meandering channel as well as high filling ratios $(30 \%-80 \%)$. The device demonstrates oscillating temperatures as seen in OHPs under certain test conditions. In other conditions, the oscillations are not read by the thermocouples, but may be dampened out by the thermal mass of the device shell. For both water and acetone, a filling ratio between $30 \%$ and $50 \%$ provided the best results. Acetone demonstrated the highest peak performance, while water provided a wider usable power input range. For acetone, the oscillations were most prevalent in the thermocouple data at low cooling bath temperatures, whereas oscillations were most prevalent for water at high cooling bath temperatures. Low power startup was achieved with the device at lower filling ratios. The device appears to have a narrow ideal operating range as demonstrated by peaks in the temperature difference curves.

\section{ACKNOWLEDGEMENTS}

The work presented in this article was funded by the Office of Naval Research Grant No. N00014-06-1-1119 directed by Dr. Mark Spector.

\section{REFERENCES}

Borgmeyer, B., Ma, H. B., 2007, "Experimental Investigation of Oscillating Motions in a Flat Plate Pulsating Heat Pipe", $J$. Thermophys. Heat Transfer, 21 (2), pp. 405-409

Chang, J. Y., Prasher, R. S., Prstic, S., Cheng, P., Ma, H. B., 2008, "Evaporative Thermal Performance of Vapor Chambers under Nonuniform Heating Conditions", J. Heat Transfer, 130 (12), pp. 121501-1 - 121501-9

Faghri, A., 1995, Heat Pipe Science and Technology, Taylor \& Francis Group, Boca Raton

Holley, B., Faghri, A., 2005, "Analysis of Pulsating Heat Pipe with Capillary Wick and Varying Channel Diameter", Int. J Heat Mass Transfer, 48, pp. 2635-2651

http://dx.doi.org/10.1016/j.ijheatmasstransfer.2005.01.013

Kammuang-Lue, N., Sakulchangsatjatai, P., Terdtoon, P., Mook, D. J., 2009, "Correlation to Predict the Maximum Heat Flux of a Vertical Closed-Loop Pulsating Heat Pipe", Heat Transfer Eng., 30 (12), pp. 961-972

http://dx.doi.org/10.1080/01457630902837442

Lee, S. H. -K., Chu, S. K., Choi, C. C. C., Jaluria, Y., 2007, "Performance Characteristics of Vapor Chambers with Boiling Enhanced Multi-Wick Structures", 23rd IEEE SEMI-THERM Symposium, art. no. 4160899, pp. 125-130

Ma, H. B., Wilson, C., Borgmeyer, B., Park, K., Yu, Q., Choi, S. U. S., Tirumala, M., 2006, "Effect of Nanofluid on the Heat Transport Capability in an Oscillating Heat Pipe", Appl. Phys. Lett., 88 (14), pp. 1161-1163.

Ma, H. B., Wilson, C., Yu, Q., Park, K., Choi, U. S., Tirumala, M, 2006, "An Experimental Investigation of Heat Transport Capability in a Nanofluid Oscillating Heat Pipe", J. Heat Transfer, 128 (11), pp. 12131216.

http://dx.doi.org/10.1115/1.2352789

Soponpongpipat, N., Sakulchangsatjaati, P., Kammuang-Lue, N., Terdtoon, P., 2009, "Investigation of the Startup Condition of a ClosedLoop Oscillating Heat Pipe', Heat Transfer Eng., 30 (8), pp. 626-642 http://dx.doi.org/10.1080/01457630802656876

Thompson, S.M., Ma, H. B., 2010, "Effect of Localized Heating Three Dimensional Flat-Plate Oscillating Heat Pipe," Advances in Mechanical Engineering, Volume 2010, Article ID 465153 , http://dx.doi.org/10.1155/2010/465153

Thompson, S.M., Ma, H. B., Winholtz, R.A., Wilson, C., 2009 , "Experimental Investigation of a Miniature Three-Dimensional FlatPlate Oscillating Heat Pipe," J. Heat Transfer, 131 (4), pp. 043210-1 043210-9 
Wilson, C., Borgmeyer, B., Winholtz, R. A., Ma, H. B., Jacobson, D., Hussey, D, "Thermal and Visual Observation of Water and Acetone Oscillating Heat Pipes", J. Heat Transfer, accepted.

Xie, H., Ali, A., Bhatia, R., 1998, "The Use of Heat Pipes in Personal Computers", Thermal and Thermomechanical Phenomena in Electronic Systems, ITHERM'98, The Sixth InterSociety Conference, Seattle, WA, USA, ISSN:1089-9870, pp. 442-448.
Xu, J., Zhang, Y., Ma, H. B., 2009, "Effect of Internal Wick Structure on Liquid-Vapor Oscillatory Flow and Heat Transfer in an Oscillating Heat Pipe", J. Heat Transfer, 131 (12), pp. 121012-1 - 121012-10. http://dx.doi.org/10.1115/1.3222736

Zuo, Z. J., North, M. T., and Ray, L., 1999, "Combined Pulsating and Capillary Heat Pipe Mechanism for Cooling of High Heat Flux Electronics," Proceedings of the ASME Heat Transfer Division, Nashville, TN. pp. 2237-2243 